\title{
Developing Electrocardiogram Mathematical Model for Cardiovascular Pathological Conditions and Cardiac Arrhythmia
}

\author{
V. V. Stuchilin ${ }^{1 *}$, V. A. Rumyantseva ${ }^{1}$ and I. S. Svirin ${ }^{2}$ \\ 'Department of IT and Electrical Engineering, The National University of Science and Technology \\ MISiS, Moscow, Russia; rumyanceva_v@mail.ru \\ 2Nordavind, Dubna, Russia
}

\begin{abstract}
The principles of modeling the electrocardiogram signals are considered. ECG interpolation model is given both for normal cardiac rhythm and for such abnormalities and pathological conditions as sinus arrhythmia, atrial, atrioventricular and ventricular extrasystole, idioventricular rhythm, fibrillation and flutter of ventricles and atriums. The models take into account noises and interference, as well as the isoline drifts.
\end{abstract}

Keywords: Cardiovascular System, Electrocardiogram, Mathematical Model

\section{Introduction}

Electrocardiogram (ECG) is a graphic representation of difference of potentials, occurring as a result of cardiac function and transferring to the surface of the body. In ECG the averaging of all action potential vectors is reflected, occurring at a definite moment of the heart functioning ${ }^{1}$. Due to the fact that the cardiography data can be obtained easily and due to the high diagnosis value of those data this investigation method has acquired wide-spread acceptance. In this regard the tasks of processing and studying electrocardiograms and the tasks of automated diagnostics are quite urgent. To solve those issues the models, such as artificial ECGs, are required both for normal cardiac rhythm and for different pathological conditions.

As a rule, in an ECG five waves can be identified: P, Q, R, S, T. Sometimes, a barely visible wave U can be observed. Wave $\mathrm{P}$ reflects the process of the atrial myocardium excitation, complex QRS depicts the ventricular systole, segment ST and wave $\mathrm{T}$ reflect the processes of the ventricular myocardium repolarization. The repolarization process is the phase when the initial resting potential of the cell membrane is restored after the action potential passed though it.

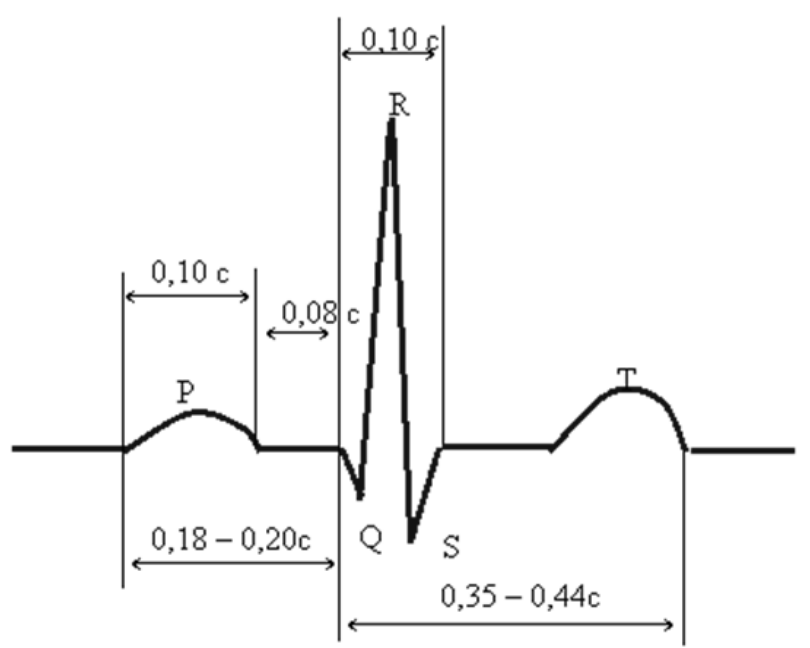

Figure 1. ECG schematic.

The schematic of ECG is shown in Figure 1. All kinks, segments and intervals with their approximate durations are shown for a healthy person ${ }^{2}$. The height of the kinks depends on the instrument applied for the measurements,

${ }^{*}$ Author for correspondence 
as well as on the derivation of the investigated signal. In this study the ECG from the database "Archive of digital recordings of physiologic signals and related data" is considered $^{3}$. The majority of the ECGs, given there, contain derivation II signal (according to Goldberger system). In database "Archive of digital recordings of physiologic signals and related data" it is designated as ECG1.

\section{Basic ECG Model with no pathological Conditions}

Consider the basic model, similar to that of ${ }^{4}$. It is formed according to template $z(t)$, which is described by the sum of symmetric Gaussian functions.
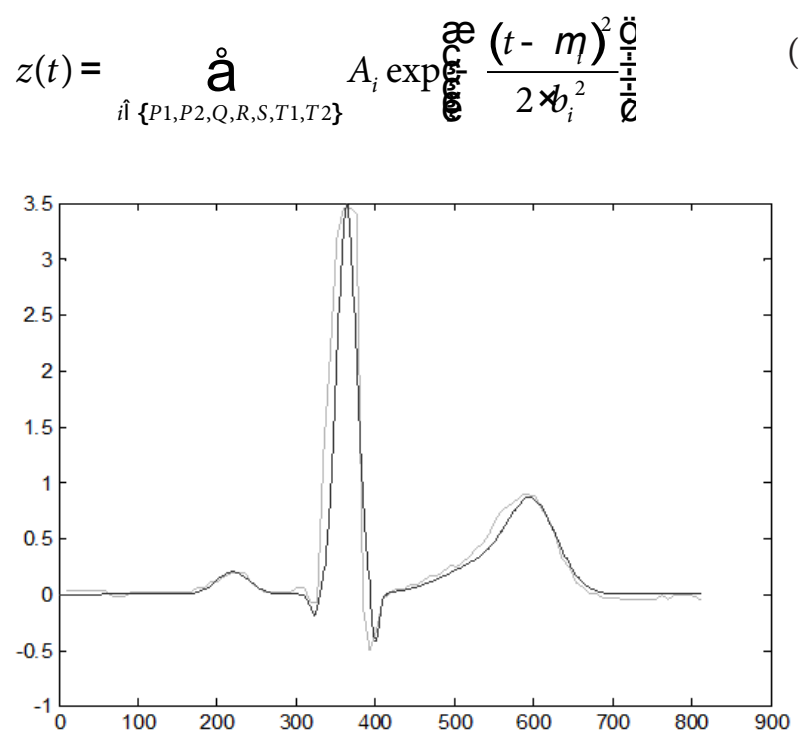

Figure 2. Basic cycle of normal ECG model. Comparing the model basic cycle with cycle record No. 16272.

In our case wave $\mathrm{P}$ is represented as the sum of two Gaussian functions, in order to model the processes in the left and in the right atriums separately. The asymmetry of kink $\mathrm{T}$ is also modeled by summing up two additive components (T1 and T2) from the sum of formula (1).

In Figure 2 a theoretical ECG is shown, computed based on the formulae, given above, and compared with record No. 16773 "MIT-BIH Normal Sinus Rhythm Database" from the database "Archive of digital recordings of physiologic signals and related data". In this Figure, as well as in all following figures, time in $\mathrm{ms}$ is indicated along horizontal axis, and the voltage in $\mathrm{mV}$ is shown along vertical axis.

The following relative values have been used for creating the basic cycle of the model:

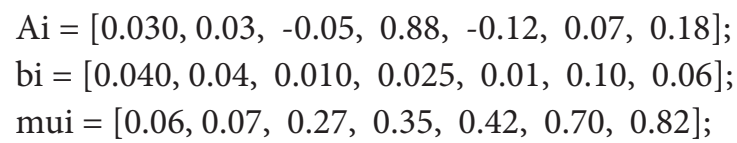

Parameters $A i$ are given in relation to the difference in heights of $\mathrm{R}$ and $\mathrm{S}$ waves. This difference can be calculated as a difference between the maximum and the minimum values of voltage within one cycle. Parameters $b i$ and $m u i$ are given in relation to general duration of excitation. According to Figure 1, under normal condition it can equal to $0.53-0.64 \mathrm{~s}$.

The model takes into account the changes in $R R$ interval duration. They are assumed to be normally distributed. Their mathematical expectation corresponds to cardiac rate $\mathrm{CR}=601 / \mathrm{min}$ (average period $\mathrm{RR}=$ $1000 \mathrm{~ms}$ ), RMSD (root-mean-square deviation) $=20 \mathrm{~ms}$. Sampling frequency is $500 \mathrm{~Hz}$. The modeled signal is affected by noise, distributed according to normal law with parameters $(\mathrm{m}=0 \mathrm{mV}, \mathrm{s}=0.02 \mathrm{mV})$.

In addition, the isoline drift is also accounted for. isoline is assumed to be changing according to sinusoidal law with frequency of $151 / \mathrm{min}$ (breath frequency) and amplitude of $0.12 \mathrm{mV}$. The model was created in MatLab software. ECG model graph for normal sinus rhythm is shown in Figure 4. In this, as well as in the following graphs

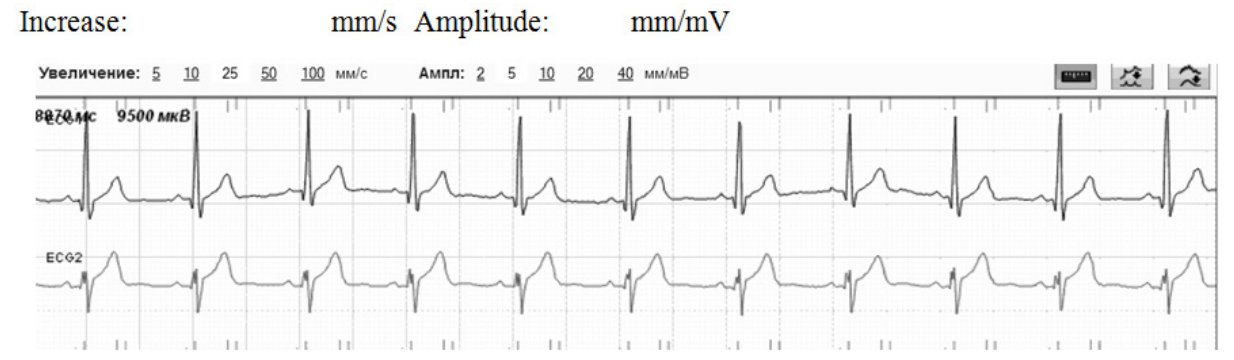

Figure 3. The normal sinus rhythm. ECG of a male aged 26 


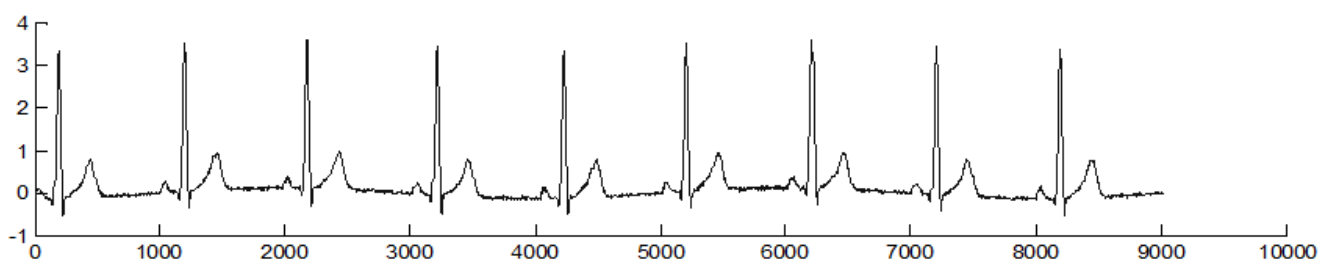

Figure 4. Modeling the normal sinus rhythm. ECG of a male aged 26.

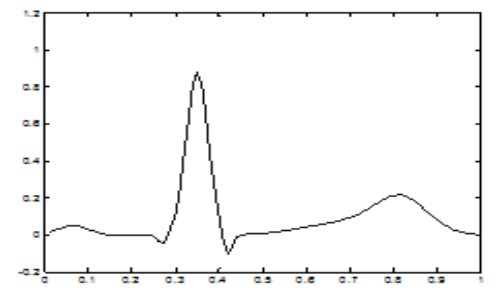

(a)

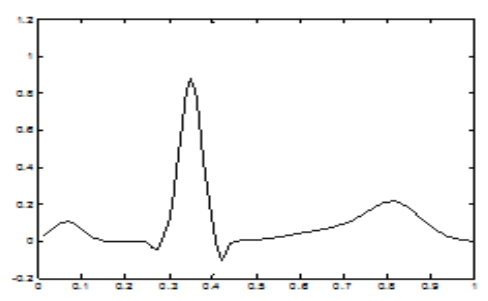

(d)

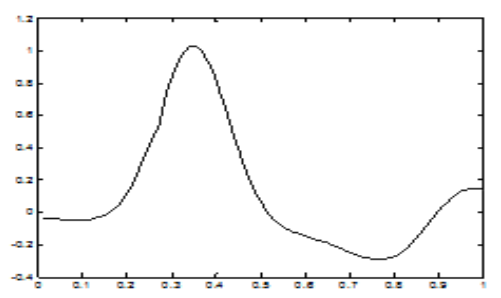

(g)

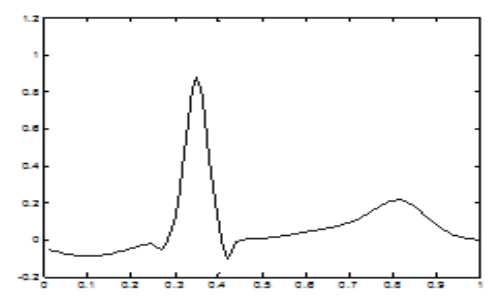

(b)

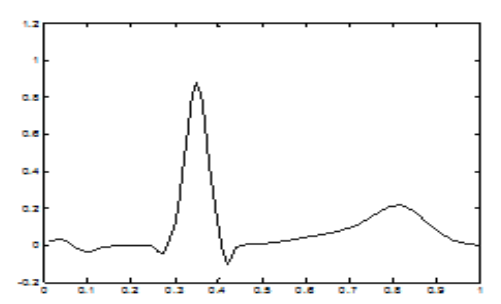

(e)

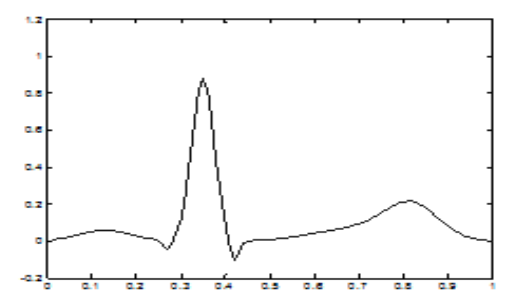

(h)

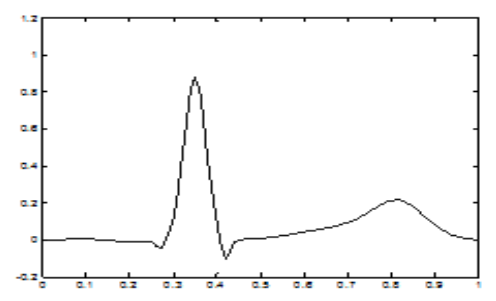

(c)

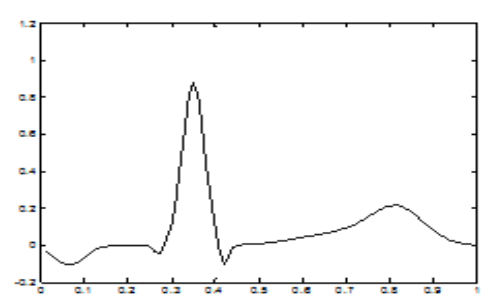

(f)

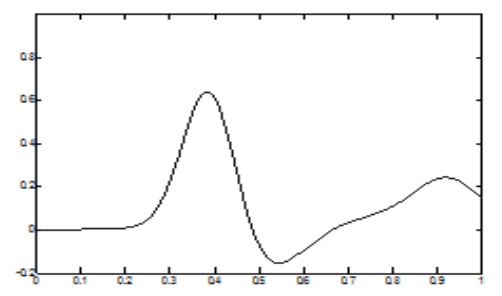

(i)

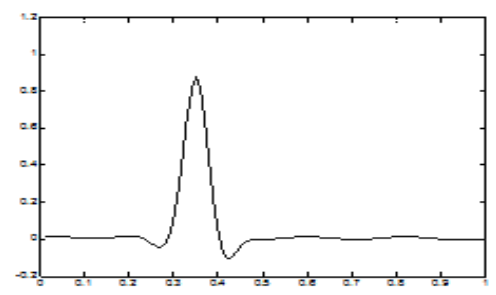

(j)

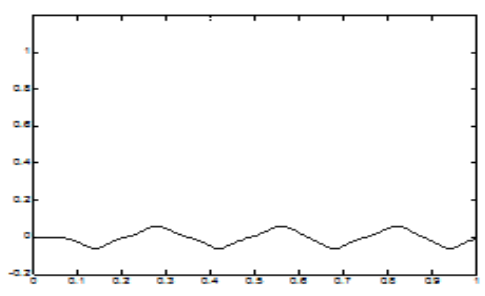

(k)

Figure 4. ECG normalized wavelet shape for different pathological conditions.

(a) No pathology ECG. (b) Atrioventricular extrasystole. (c) Atrioventricular extrasystole (the source of extrasystolic contraction is in the centre of AV-node); atrial extrasystole. (d) Upper. (e) Middle. (f) Lower atrial. (g) Ventricular extrasystole. (h) Atrioventricular rhythm. (i) Idioventricular rhythm. (j) Atrial flutter. (k) Ventricular fibrillation wavelets. 
of artificial ECGs (Figures 6, 7, 8) time in milliseconds is indicated along horizontal axis and potential in millivolts is indicated along the vertical axis.

\section{Arrhythmia and Cardiovascular Pathologic Conditions}

Consider the principles of creating ECG model for different pathologic conditions.

Sinus arrhythmia is characterized by the fact that, so far as the excitation takes place in the sinus node, the general shape of all waves and their durations remain the same as they were in the basic model. Only the pulse repetition period will change. In sinus tachycardia the repetition period decreases, and in bradycardia it increases. In sinus arrhythmia the period will be changing considerably. This can be modeled by increasing the root-mean-square deviation of the period.

Such heart rhythm disorder as extrasystole is observed when in different sections of the heart the focus of pathological, out-of-phase contractions occur, which take place at the background of the usual, "correct" contractions. The shape of the wave of extrasystole contraction depends on where the focus is situated. Consider the peculiar features of modeling the kink shapes in the graphs of normalized functions.

The shape of normalized impulse is set by numeric values of quotients $A_{\mathrm{i}}, b_{\mathrm{i}}$ and $m_{\mathrm{i}}$. In Figure 5 the basic,

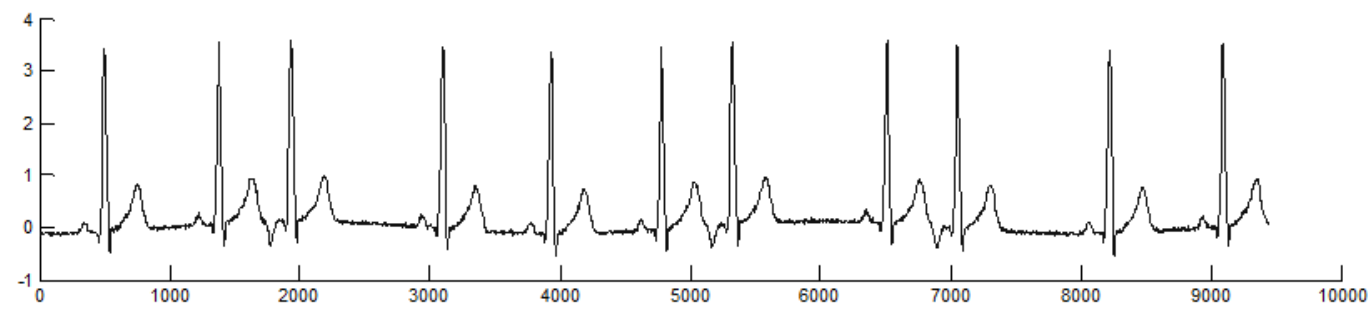

(a)

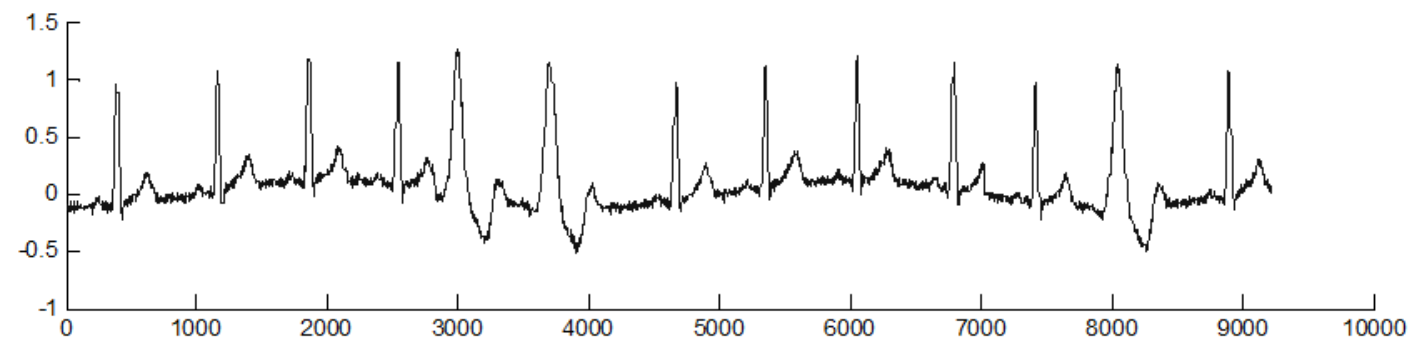

(b)

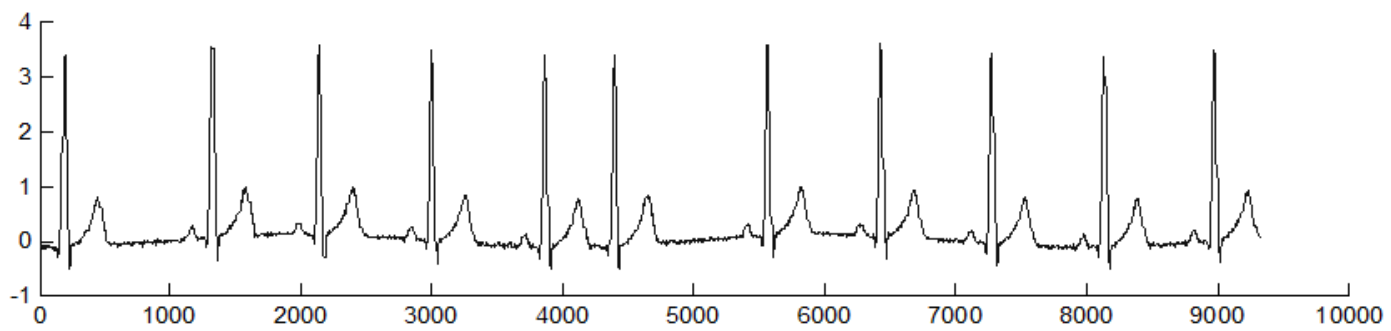

(c)

Figure 6. Extrasystole ECG model. (a) Lower atrial extrasystole. (b) Ventricular extrasystole. (c) Atrioventricular extrasystole. 
normalized graphs of heart contractions with different types of pathological conditions are shown. The coordinate axes are non-dimensional.

ECG model in extrasystole functions as follows. Before forming each of the impulses, it is determined, with specified probability, what type the next contraction will be: normal as shown in Figure 5(a) or extrasystolic as shown in Figure 5(b)-(d). In case of normal contraction the excitation is shifted in time towards the end of the period, and in case of extrasystolic contraction there is no such shift. Thus, the fact is modeled, that extrasystolic, out-of-phase, contraction occurs earlier than the normal one.

Such pathological conditions as atrioventicular, ventricular (idioventricular) and atrial types of tachycardia occur due to the fact that in a relevant section of the heart the ectopic focus appears, where the feedback connection is closed and the high frequency impulses generation starts. This focus undertakes the full function of the cardiac pacemaker. In modeling such ECG all contractions are transfigured according to Figure 5(f), (h), (i). The period is selected according to the preset value of Cardiac Rate (CR) for the relevant pathological condition (as a rule, 120-150 1/min). If the obtained period is less than the time of excitation, then the functions in the model are superimposed on one another by simple summarizing. The models, built in such a way, are shown in Figure 7.

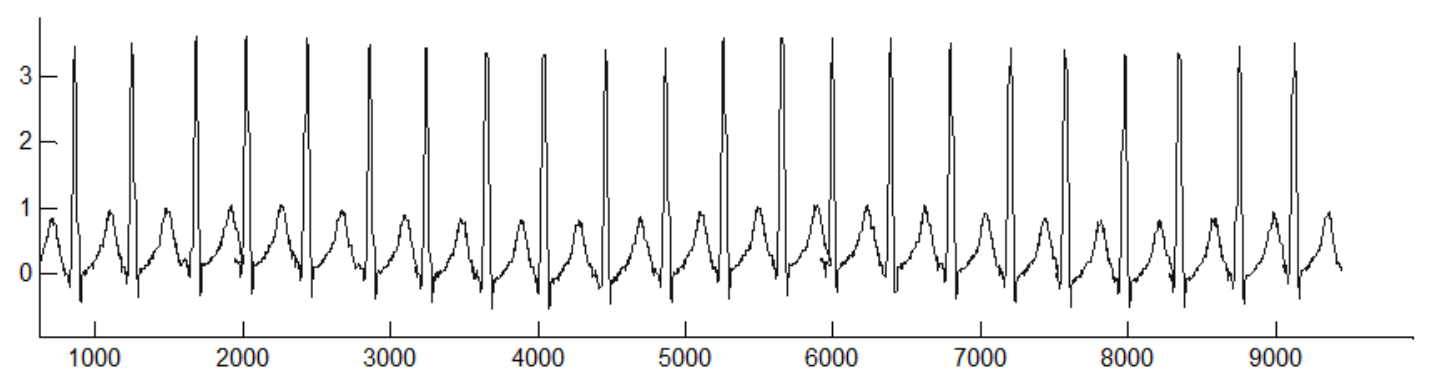

(a)

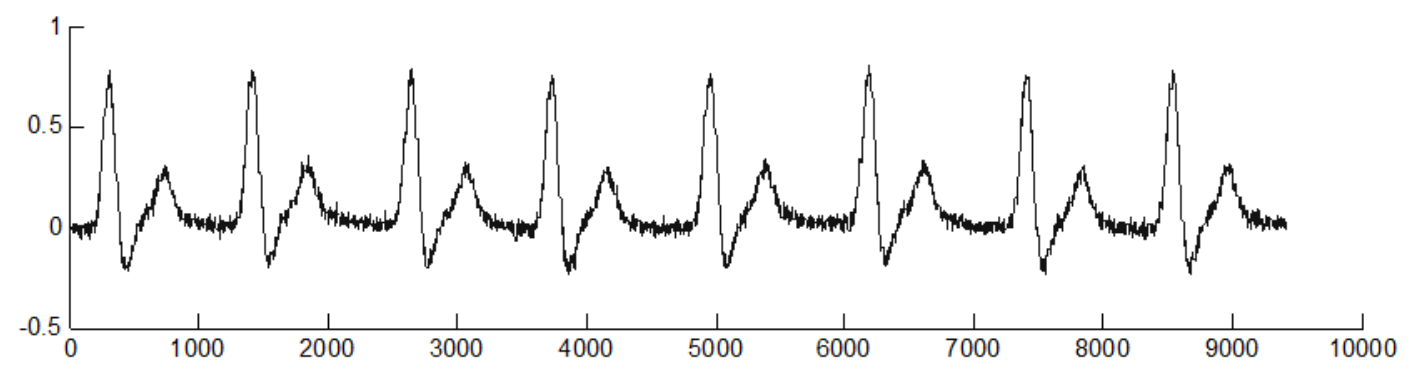

(b)

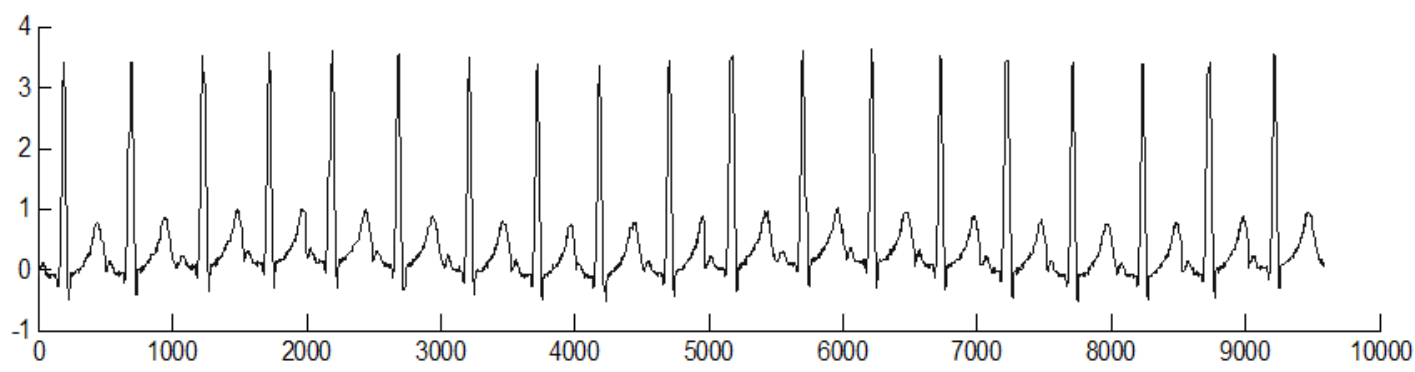

(c)

Figure 7. Models. (a) Atrioventricular rhythm. (b) Idioventricular rhythm. (c) Atrial rhythm. 
The shape of contraction in atrioventricular tachycardia is shown in Figure 5(e). Complex QRS is not changed, wave $\mathrm{P}$ is missing. In atrial tachycardia kink $\mathrm{P}$ is transfigured, it is superimposed on wave $\mathrm{T}$. In ventricular tachycardia complex QRS is transfigured considerably, its shape is shown in Figure 5(i). It was obtained based on graphic data of ${ }^{5}$

The models of atrial and ventricular fibrillations and flutter are shown in Figure 8. Atrial flutter is characterized by the fact that QRS complex occurs at the background of so-called flutter waves, which represent a transfigured kink P, repeated with very high frequency $220-2501 / \mathrm{min}$, which is associated with the presence of the self-excitation ectopic focus in atrium. As far as the heart can not contract with such high frequency, QRS complex follows with lower frequency, but, nevertheless, periodically shown in Figure 8(a).

In atrial fibrillation several self-excitation focus occur with their own frequency. Therefore, the periodicity of such ECG will be disturbed much more considerably as in Figure 8(b). In this case QRS complex occurs at the background of fibrillation waves, which shape is shown in Figure 5(k), and which are superimposed on one another at random. In modeling ventricular flutter and fibrillations

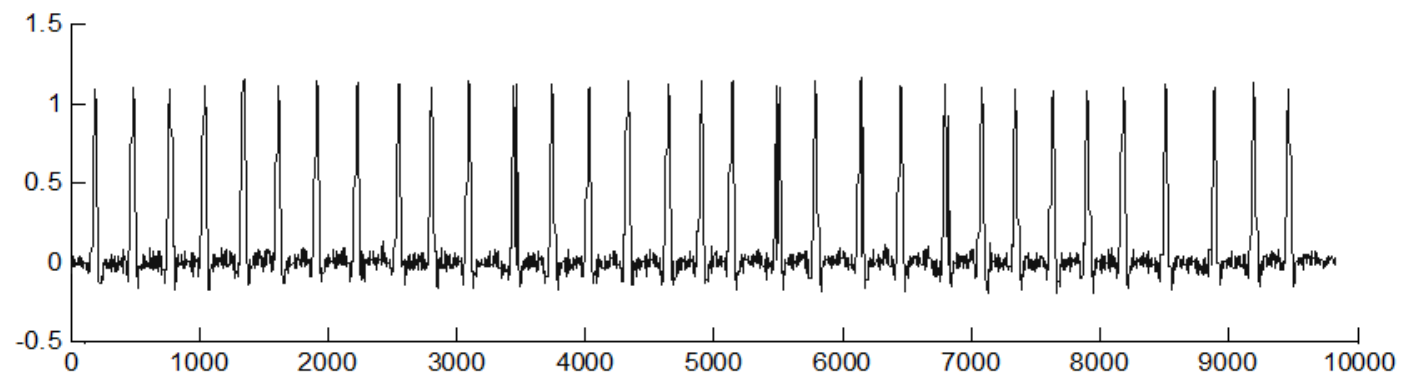

(a)

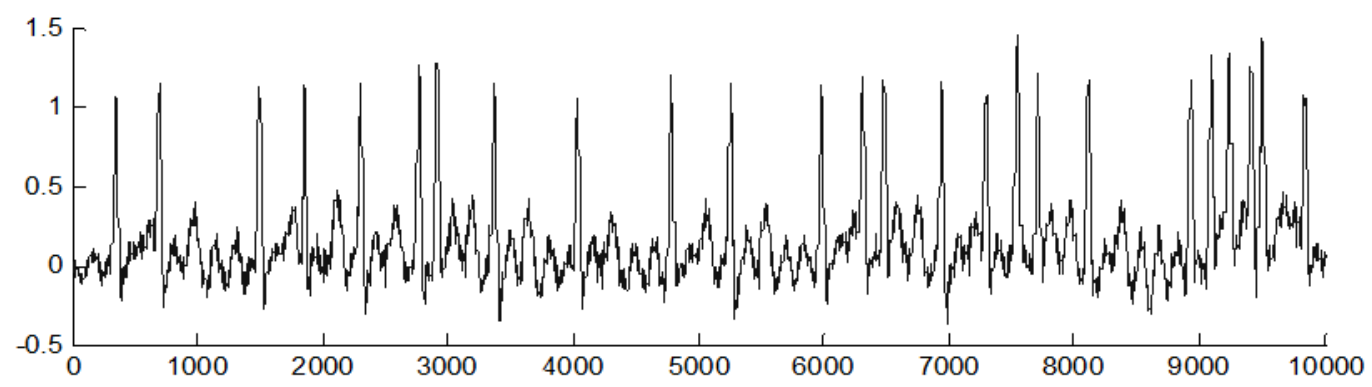

(b)

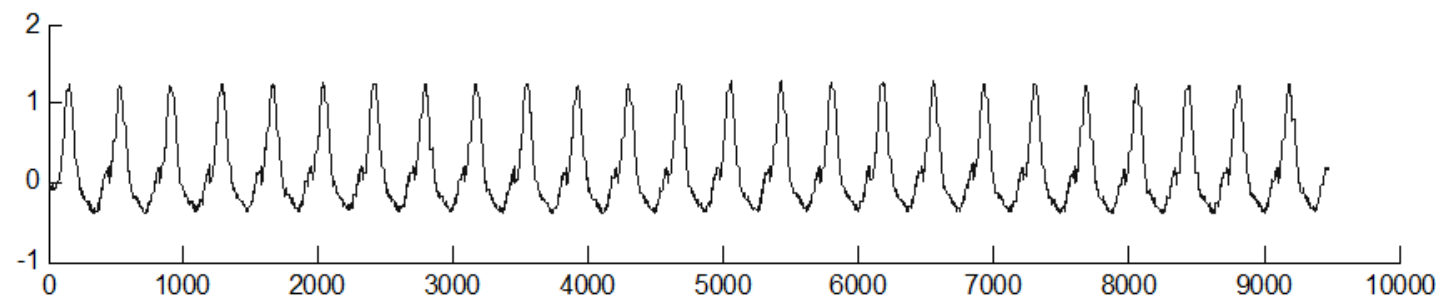

(c) 


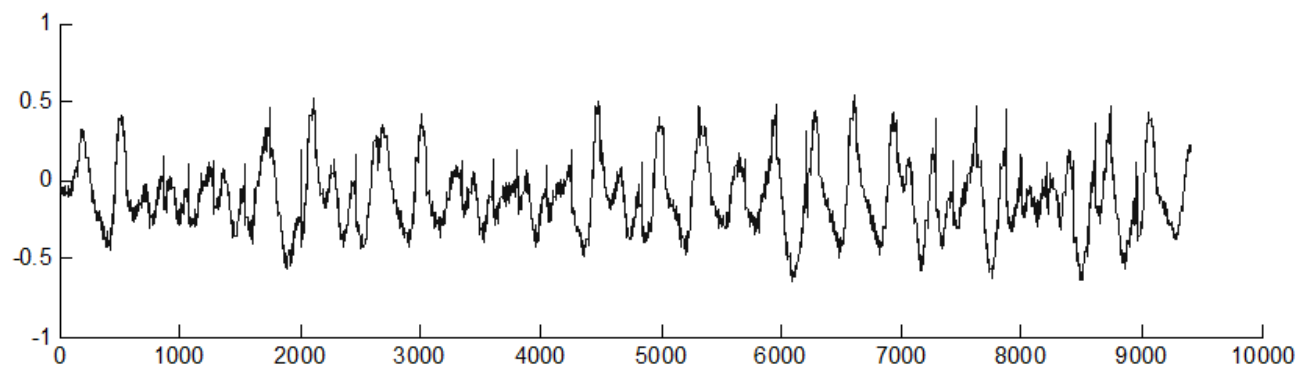

(d)

Figure 8. Models. (a) Atrial flutter. (b) Atrial fibrillation. (c) Ventricular flutter. (d) Ventricular fibrillation.

the basic shape was used Figure 5(g). Ventricular flutter is associated with the presence of one self-excitation focus in the ventricle, therefore, ECG signal is periodic as shown in Figure 8(c), but fibrillation is associated with the presence of several loci, therefore, the signal is chaotic to such a degree as shown in Figure 8(d), that it is hard to trace any periodicity at all. For the purposes of modeling, the period, corresponding to cardiac rate of $\mathrm{CR}=240 \mathrm{1} /$ min, was selected, RMSD of the period was assumed to be equal to $1 / 3$ of the period.

\section{Conclusion}

The models, described above, can be used in developing the algorithms for automated analysis of the electrocardiography results and for establishing the preliminary diagnosis.

\section{Acknowledgment}

The study was developed within the framework of federal target program "Research and development on priority directions of scientific-technical complex of Russia for 2014-2020 years", Agreement No. 14.576.21.0083 dd. 28.11.2014 on the subject "Developing the mobile medical system software for individual electro- physiological diagnostics of cardiovascular diseases based on implementing modern algorithms of digital signal processing and pattern recognition".

\section{References}

1. Ardashov AV, Loskutov AY. Practitcheskiye aspekty sovremenykh metodov analiza variabelnosti serdetchnogo ritma [Practical aspects of modern methods of analyzing the cardiac rhythm variability]. Moscow: Medpraktika-M; 2010. p. 128. [in Russian].

2. Shutchko AA. EKG pod silu kazhdomu [ECG is within everyone's power]. Minsk: Varaksin AN; 2014. p. 160. ISBN: 978-985-7092-77-2. Available from: http://medfors.ru/videokurs-ekg [in Russian].

3. Archive of digital recordings of physiologic signals and related data. Available from: http://www.beecardia.com/ physiobank

4. Bekler TY. Modelirovaniye iskustvenikh elektrokardiogram normalnoy i patologitcheskoy formy [Modeling artificial electrocardiograms of normal and pathological forms]. Kibernetika i vichislitelnaya tekhnika [Cybernetics and Computer Engineering]. 2012; 169. ISSN: 0452-9910. [in Russian]

5. Batkin IZ. Osnovy klinitcheskoy elektrokardiografii. Interaktivnoye multimediynoye utchebnoye posobiye dlya studentov i vratchey [Basics of clinical electrocardiography. Interactive multimedia tutorial for students and doctors]. Khabarovsk, 2000; Available from: http://www.fesmu.ru/ www2/PolTxt/U0007/start.htm [in Russian]. 